\title{
Timing is everything: cell cycle control of Rad52
}

\author{
Jacqueline H Barlow', Rodney Rothstein ${ }^{2 *}$
}

\begin{abstract}
Regulation of the repair of DNA double-strand breaks by homologous recombination is extremely important for both cell viability and the maintenance of genomic integrity. Modulation of double-strand break repair in the yeast Saccharomyces cerevisiae involves controlling the recruitment of one of the central recombination proteins, Rad52, to sites of DNA lesions. The Rad52 protein, which plays a role in strand exchange and the annealing of single strand DNA, is positively regulated upon entry into $S$ phase, repressed during the intra-S phase checkpoint, and undergoes posttranslational modification events such as phosphorylation and sumoylation. These processes all contribute to the timing of Rad52 recruitment, its stability and function. Here, we summarize the regulatory events affecting the Rad52 protein and discuss how this regulation impacts DNA repair and cell survival.
\end{abstract}

\section{Introduction to double-strand break repair}

Double-strand breaks (DSBs) can be repaired by two major pathways, non-homologous end-joining (NHEJ) or homologous recombination (HR). NHEJ directly rejoins broken DNA ends by ligation [1,2], while HR utilizes a homologous DNA template to prime DNA synthesis and restores genetic information lost at the break site (Figure 1; [3-5]). Both NHEJ and HR follow stepwise pathways leading to repair that involve distinct sets of proteins. In both pathways, the MRX complexcomprised of Mre11, Rad50 and Xrs2-first recognizes and binds the exposed ends of the DSB [6-10]. In NHEJ, the yeast $\mathrm{Ku} 70 / \mathrm{Ku} 80$ heterodimer also recognizes and binds the DNA ends. Ku70/Ku80 then recruits the Lif1/ Nej1 heterodimer and Lif1 both recruits and stimulates Dnl4 ligase activity to complete repair [1,11-14]. Processing of the ends for NHEJ is limited, and NHEJ itself is potentially mutagenic, resulting from the loss of genetic material at the break/join site.

Homologous recombination, on the other hand, rejoins the DNA ends faithfully using a homologous template for repair and requires the Rad52 epistasis group of proteins $[4,5]$. Initiation of HR begins with processing of the DSB ends by one or more nucleases into 3' single strand DNA (ssDNA) tails $[4,15,16]$. The ssDNA is bound by RPA, which also recruits the checkpoint complex Mec1-Ddc2, homologs of vertebrate ATR-ATRIP respectively $[6,17]$. Rad52, a central component of the yeast HR machinery,

\footnotetext{
* Correspondence: rothstein@cancercenter.columbia.edu

${ }^{2}$ Department of Genetics \& Development, Columbia University Medical Center, 701 West 168th Street, HHSC 1608, New York, NY 10032-2704, USA
}

catalyzes the assembly of the RecA homologue Rad51 into a long nucleoprotein filament, the displacing RPA from the ssDNA tails [18-21]. This filament initiates the homology search using the sequence to be repaired-the "acceptor"-to find a repair template-the "donor" of genetic information. Once a homologous template is found, the nucleoprotein filament engages in strand invasion involving the Swi/Snf homolog Rad54 [22]. The Rad55/Rad57 complex stabilizes the Rad51/DNA filament promoting strand pairing and exchange $[23,24]$. Figure 2 shows three possible outcomes for the repair of a DSB by HR after invasion of one end. In canonical double-strand break repair (DSBR) (Figure 2A), second end capture-likely catalyzed by the annealing activity of Rad52-results in both ends of the DSB invading the acceptor [25]. DNA replication primed from both donor 3 ' ends leads to the formation of a joint molecule containing two Holliday junctions. In synthesis-dependent strand annealing (SDSA, Figure 2B) new DNA synthesis occurs along only one strand, which is subsequently displaced by a DNA helicase. The resultant ssDNA tail contains complementary sequence capable of annealing to the other DSB end. In this case, an additional role for Rad52 is to catalyze annealing to form duplex DNA between the 3' tails [26-28]. Any resulting gaps are filled by DNA replication. In the absence of second-end capture and/or SDSA, break-induced replication (BIR) can occur (Figure 2C). In BIR, the single DNA end that invades the homologous chromosome primes new DNA synthesis, which proceeds until it reaches the end of the chromosome [4,5,29-31].

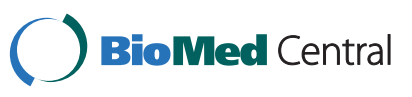


G1

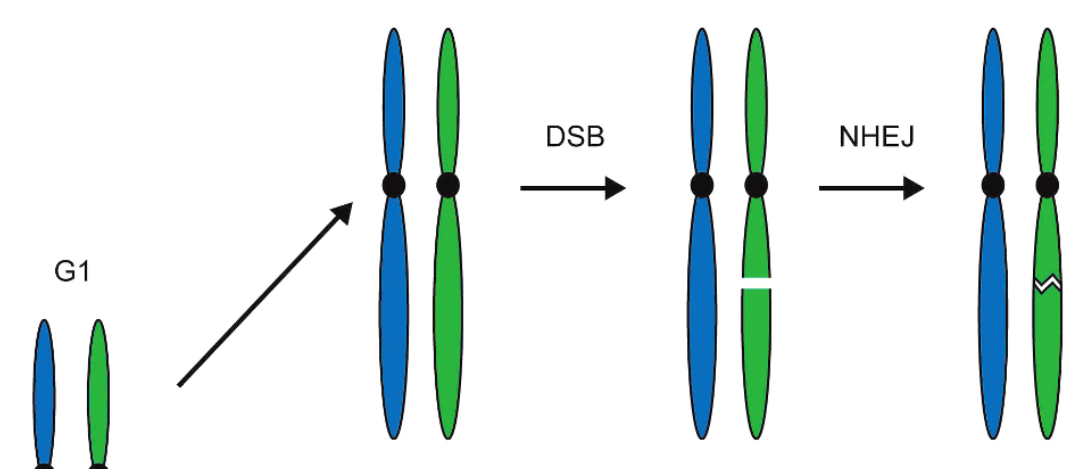

G2
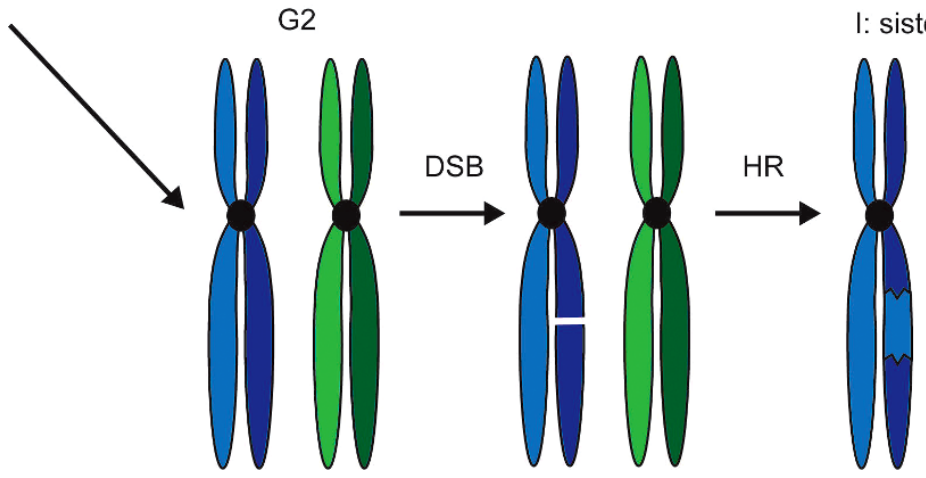

sister chromatid

II: homolog

Figure 1 Repair of a DSB proceeds according to cell cycle stage. In G1, cells have a single copy of each chromosome (light blue and light green). If a break occurs in G1, the cell repairs the DSB by NHEJ, directly resealing the DNA ends (top). In G2, after chromosomes have been replicated, there is a sister chromatid, an identical copy of each original chromosome (dark blue and dark green, bottom). When a DSB occurs in $\mathrm{G} 2$, it is normally repaired by HR using either the sister chromatid or a homologous chromosome as a template. Repair from the sister (I) results in restoration of the exact information lost at the break site. Repair from the homolog (II), however, may lead to loss of heterozygosity if accompanied by a crossover.

\section{Cell cycle regulation of homologous recombination}

Double-strand break repair is highly coordinated with the cell cycle: NHEJ occurs primarily in G1 while $\mathrm{HR}$ takes place predominantly during $\mathrm{S}$ and $\mathrm{G} 2 / \mathrm{M}$ $[3,4,7,32,33]$. The major cell cycle kinase, CDK1-Cdc28 in S. cerevisiae-lies at the heart of the cell cycle regulation of DSBR CDK1 regulates the initiation of $\mathrm{HR}$ at two distinct levels: 1) DNA resection and 2) recruitment of Rad52 itself. Extensive resection of DSB ends only occurs in the presence of the high CDK1 activity in $\mathrm{S}$ and G2/M [34-36]. The MRX-associated nuclease Sae2-CtIP in vertebrates-aids in the processing of broken DNA ends along with the helicase Sgs1, and the Exo1 and Dna2 nucleases [37-42]. CDK1 phosphorylates Sae2, promoting highly processive DNA resection upon entry into $S$ phase [43]. The result is long tracts of 3' ssDNA flanking the break site. Relocalization of repair proteins to DSBs, such as RPA, can be visualized as subnuclear foci [44]. When RPA binds ssDNA exposed in
G1 cells, the foci formed are observably smaller and less intense than those in $\mathrm{S}$ and G2/M cells, perhaps reflecting the difference in resection rate between these cell cycle states [45].

During S and G2/M, Rad52 recruitment is dependent upon RPA, although RPA bound to ssDNA is not sufficient for Rad52 recruitment in G1 [6,45]. Studies have shown that CDK1 activity is also required for the recruitment of Rad52, even in the presence of RPA-bound ssDNA [46,47]. Interestingly, Rad52 recruitment to DSB sites does not rely on DNA replication per se, as cells that have entered $\mathrm{S}$ phase, but have not replicated their DNA, readily form Rad52 foci in response to DNA damage $[46,47]$. Exactly how CDK1 regulates this process is unknown. Perhaps CDK1 acts directly on the Rad52 protein itself or phosphorylates an upstream factor like RPA. Both of these proteins are good candidates sincelike Rad52 (see below)-Rfa2 is also phosphorylated in a cell cycle-dependent manner and in response to genotoxic stress [48-53]. In addition, phosphorylation of the 


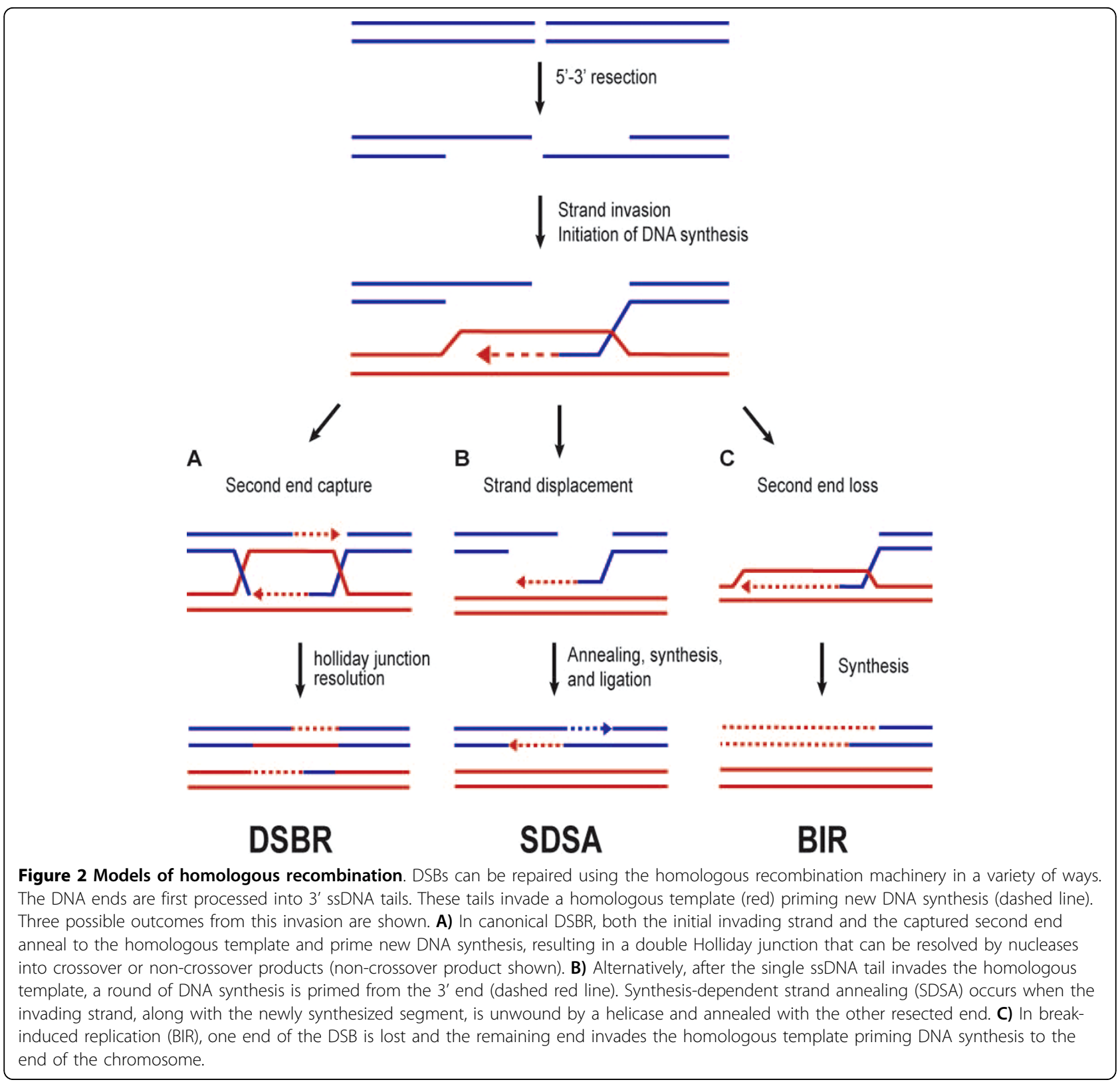

$\mathrm{N}$-terminus of human Rpa2 by CDK1 is important for DNA repair as cells expressing a non-phosphorylatable form of Rpa2 exhibit an altered cell cycle profile and a persistent DNA damage signal [54].

\section{Regulation of HR during DNA replication}

Cells are most vulnerable to genomic insults during DNA replication and entry into $\mathrm{S}$ phase. In preparation for DNA replication, a series of protein complexes bind sequentially to specific DNA sequences in a process termed origin licensing [55-58]. Proper origin licensing during G1 is essential for rapid and faithful DNA replication during $\mathrm{S}$ phase, as origins are unable to re-license until the cell has progressed through the cell cycle to $M$ phase [59]. DNA replication initiates by origin firing, when the replisome-including the DNA helicase encoded by Mcm2-7, the DNA replication clamp PCNA and both the leading and lagging strand polymerasesmoves away from origins and DNA synthesis begins. Damage can arise during replication by mechanical stress on the DNA itself or if the replisome encounters covalently attached DNA adducts. Lesions may also arise if replication does not proceed efficiently, leading to the uncoupling of DNA unwinding and new DNA synthesis. To maintain genomic integrity, a number of mechanisms have evolved both to stabilize DNA during 
replication and to activate specific $S$ phase checkpoints in the event of DNA damage (see Figure 3).

The checkpoint kinase Mec1 and its activation partner Ddc2 play key roles in genome stability during $\mathrm{S}$ phase. Mec1 kinase activity and its downstream effector kinase Rad53 are required to stabilize stalled forks and activate the intra-S phase checkpoint [60-62]. Mec1 phosphorylates Mrc1, an intra-S phase checkpoint protein associated with the replication fork, and promotes restart of stalled forks [63-65]. Furthermore, Mrc1 is required for the accumulation of Mec1 at stalled forks, independently of Rad53 activity [63]. Mrc1 physically inhibits the uncoupling of the replicative helicase from the leading strand polymerase, locking both halves of the replisome at the stalled fork $[53,66]$. How these checkpoint complexes interact with the recombination machinery in $\mathrm{S}$ phase is not well understood.

Hydroxyurea (HU), a potent ribonucleotide reductase inhibitor, decreases dNTPs pools and stalls replication forks, activating the intra-S phase checkpoint. In the presence of HU, Rad52 is unable to form either spontaneous or damage-induced recombination foci $[6,46,47]$. In addition, the rate of resection at DSBs is significantly reduced during $\mathrm{HU}$-mediated $\mathrm{S}$ phase arrest, leading to a reduction in ssDNA formation [46]. One argument is that the amount of RPA-bound ssDNA is limited and

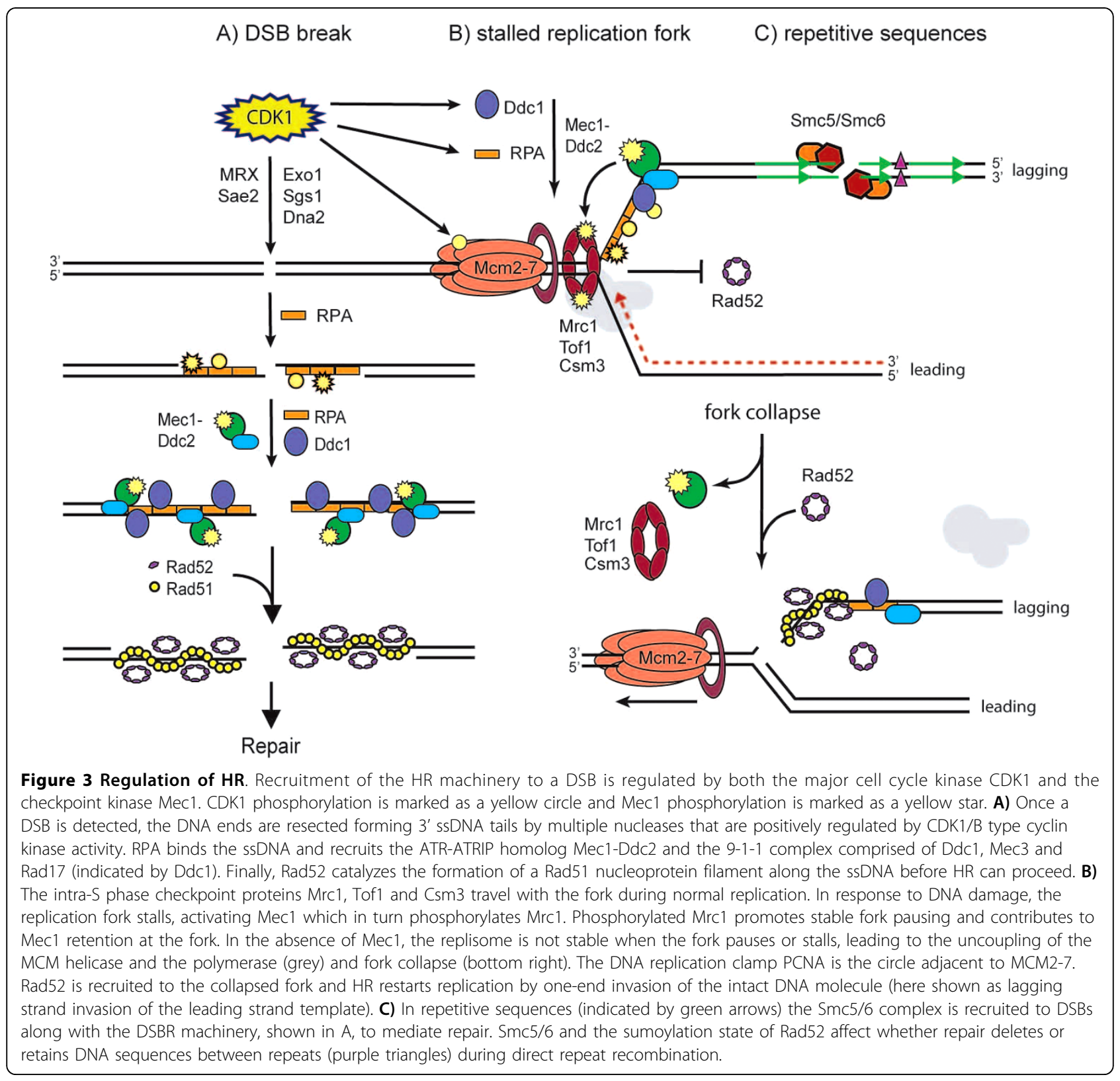


may not be sufficient to recruit Rad52. However, even during HU arrest, IR-induced DNA breaks undergo enough resection to form RPA foci and still do not form Rad52 foci [47]. These results suggest that a simple model hinging on available RPA-bound ssDNA does not fully explain the complete absence of Rad52 foci Therefore we propose that the intra-S phase checkpoint imposes an additional level of regulation, suppressing Rad52 foci both at stalled replication forks and at DSBs. This regulation is likely performed by Mec1, since suppression of Rad52 foci in HU is Mec1/Rad53-dependent [47]. However Rad52 is not a direct target of either the Mec1 or Rad53 kinases ([67]; AAM, unpublished data). Interestingly, in S. pombe, Rad52 does associate with stalled replication forks; however, the levels are too low to form observable foci [68]. These results indicate that low-level Rad52 association is important to initiate recombination in case of fork collapse, although the precise function of Rad52 at stalled forks is unknown. In budding yeast, it is clear that the recruitment of the HR machinery to stalled forks is detrimental to cell survival. This notion is supported by the fact that HR is toxic in the absence of proteins necessary to resume replication, in particular Top3, Sgs1, and Srs2 [69-72].

Although HR is inhibited at stalled replication forks, it is necessary to permit HR during $S$ phase for cell survival in the event of fork collapse. In support of this idea, spontaneous Rad52 foci are observed in $50 \%$ of S phases [73]. The HR machinery-in particular Rad51 and Rad52-plays an important role in replication fork restart, an event where a one-ended DNA fragment is generated (Figure 3; $[4,5])$. Interestingly, this view of replication fork restart resembles BIR, which also couples Rad52-mediated invasion of a one-ended DNA break with extensive DNA replication (Figure 2C). Furthermore, loss of either Rad51 or Rad52 is synthetic lethal In a Mec1- or Mrc1-deficient background, suggesting that both of these proteins are required for the restart of collapsed forks [74,75]. Thus, repair of the resulting DNA break requires many of the same components involved in canonical DSBR (Figure 3).

\section{Regulation of Rad52 activity by posttranslational modification}

The S. cerevisiae Rad52 protein is phosphorylated both constitutively and upon entry into $\mathrm{S}$ phase. These phosphorylation events occur in the $\mathrm{C}$ terminus, although the exact residues and phenotypic effects of loss of phosphorylation have yet to be determined [48]. Interestingly, Rad52 does not exhibit further phosphorylation upon exposure to DNA damaging agents. Furthermore, these multiple phosphorylation events are Mec1 and Tel1 independent, underscoring their damage-independent nature [48]. Although CDK1 activity is required for Rad52 recruitment to foci, it is unclear whether CDK1 is directly responsible for Rad52 cell cycle-dependent phosphorylation. A tantalizing possibility is that CDK1dependent phosphorylation of RPA regulates Rad52 recruitment only after the cell has entered into $\mathrm{S}$ phase.

In addition to phosphorylation, Rad52 also undergoes sumoylation on its $\mathrm{N}$ terminus and in the central domain at lysines 10, 11 and 220, in an Ubc9-dependent manner [76]. Mutation of these residues leads to a loss of sumoylation on Rad52, yet it does not affect overall HR levels or Rad52 recruitment to DNA damage. On the other hand, loss of Rad52 SUMO species does decrease protein stability and affect the outcome of direct repeat recombination, specifically decreasing events that delete intervening DNA [76]. In the absence of Rad52 sumoylation, recombination at rDNA is also affected, a locus consisting of 100-200 tandem repeats of the ribosomal genes that resides in the nucleolus. Non-sumoylatable Rad52 forms foci in the nucleolus and shows an increase in rDNA recombination, where wild-type Rad52 foci are normally excluded from the nucleolus [77]. Interestingly, regulation of Rad52 focus formation at rDNA also requires the Smc5/6 complex, which removes cohesion during mitotic exit for proper chromosomes segregation and is itself involved in sumoylation [78,79]. Together, these results suggest a link between the resolution of recombination intermediates at highly repetitive DNA to chromosome segregation during mitosis.

\section{Conclusions}

Regulation of Rad52 affects double strand break repair by initiating and/or directing many aspects of HR. Cell cycle regulation of its recruitment inhibits initiation of homologous recombination processes in G1. Checkpoint regulation of Rad52 blocks its recruitment to stalled DNA replication forks allowing them to restart independently of HR. These regulatory mechanisms help suppress potentially mutagenic or lethal recombination events in different ways. Limiting resection of the DNA ends and inhibiting the recruitment of HR proteins in G1 allows cells to repair DSBs by NHEJ with little to no information lost at the break site. After DNA replication however, the cell contains a sister chromatid, which is an identical template for repair and thus recombination is non-mutagenic (Figure 1). In diploid cells, repair can proceed from the homologous chromosome potentially leading to loss of heterozygosity that impacts the oncogenic transformation of cells by homozygosing deleterious mutations, resulting in widespread genomic instability.

However, the cell does not wait for the completion of replication to begin HR, as Rad52 is recruited into damage-induced foci early during $S$ phase $[47,73]$. Entry into $\mathrm{S}$ phase may present a point in the cell cycle where the repair of a potentially lethal lesion such as a DSB that occurred in G1 must undergo non-conservative 
recombination before replication can proceed. At this stage, the cell may repair the DSB using the homologous chromosome as a template, again with the potential for loss of heterozygosity. Alternatively, the break can be repaired using a non-homologous or homeologous sequence to promote cell survival. Depending on the choice of the sequence used to template the repair, the outcome may result in the loss of DNA flanking the break site. Furthermore, SUMO-modified forms of Rad52 affect DNA repair within repetitive sequences. How these alternate forms of Rad52 mediate template choice is unclear and elucidating their roles will impact our understanding on how DNA repair proceeds.

Finally, it is not only necessary to restrict the activity of recombination to different stages of the cell cycle, it is also important to complete the process appropriately. Future studies will clarify how Rad52 and other members of the HR machinery dissociate from the repaired DNA, adding another level of Rad52 regulation. For example, the Srs2 helicase antagonizes Rad51 filament formation that occurs independently of Rad52 but does not efficiently remove Rad52 protein, which may mark true recombination sites [80]. Other chromatin remodeling enzymes/complexes such as Rdh54, Ino80 or Rsc may also be involved in the dissolution of HR complexes. In the end, the co-ordination of recombination in budding yeast revolves around the Rad52 protein for integration of checkpoint and cell cycle signals necessary to coordinate an appropriate repair response.

\section{Acknowledgements}

We would like to thank Adriana Antunez de Mayolo for the contribution of unpublished data, Lorraine Symington, Michael Lisby, Sergio GonzalezBarrera, Michael Chang, and Kara Bernstein for their helpful comments on the manuscript. This work was supported by grant GM50237 (RR), GM67055 (RR), GM70088 (JHB) and GM73568 (JHB) from the NIH.

\section{Author details}

${ }^{1}$ Experimental Immunology Branch, National Cancer Institute, National Institutes of Health, Building 10, Room 4B04, 10 Center Drive, Bethesda, MD 20892, USA. ²Department of Genetics \& Development, Columbia University Medical Center, 701 West 168th Street, HHSC 1608, New York, NY 100322704, USA.

\section{Authors' contributions}

$\mathrm{JHB}$ and RR drafted and approved the final manuscript.

\section{Competing interests}

The authors declare that they have no competing interests.

Received: 22 January 2010

Accepted: 23 February 2010 Published: 23 February 2010

\section{References}

1. Daley JM, Palmbos PL, Wu D, Wilson TE: Nonhomologous end joining in yeast. Annu Rev Genet 2005, 39:431-451.

2. Taylor EM, Lehmann AR: Conservation of eukaryotic DNA repair mechanisms. Int J Radiat Biol 1998, 74:277-286.

3. Aguilera A, Rothstein R: Molecular Genetics of Recombination BerlinHeidelberg: Springer 2007.
4. Paques F, Haber JE: Multiple pathways of recombination induced by double-strand breaks in Saccharomyces cerevisiae. Microbiol Mol Biol Rev 1999, 63:349-404.

5. Symington LS: Role of RAD52 epistasis group genes in homologous recombination and double-strand break repair. Microbiol Mol Biol Rev 2002, 66:630-670.

6. Lisby M, Barlow JH, Burgess RC, Rothstein R: Choreography of the DNA damage response: spatiotemporal relationships among checkpoint and repair proteins. Cell 2004, 118:699-713.

7. Moore JK, Haber JE: Cell cycle and genetic requirements of two pathways of nonhomologous end-joining repair of double-strand breaks in Saccharomyces cerevisiae. Mol Cell Biol 1996, 16:2164-2173.

8. Nelms BE, Maser RS, MacKay JF, Lagally MG, Petrini JH: In situ visualization of DNA double-strand break repair in human fibroblasts. Science 1998, 280:590-592.

9. Tomita K, Matsuura A, Caspari T, Carr AM, Akamatsu Y, Iwasaki H, Mizuno K, Ohta K, Uritani M, Ushimaru T, et al: Competition between the Rad50 complex and the Ku heterodimer reveals a role for Exo1 in processing double-strand breaks but not telomeres. Mol Cell Biol 2003, 23:5186-5197.

10. Usui T, Ogawa $H$, Petrini $\mathrm{JH}$ : A DNA damage response pathway controlled by Tel1 and the Mre11 complex. Mol Cell 2001, 7:1255-1266.

11. Ahnesorg P, Jackson SP: The non-homologous end-joining protein Nej1p is a target of the DNA damage checkpoint. DNA Repair (Amst) 2007, 6:190-201.

12. Chen L, Trujillo K, Ramos W, Sung P, Tomkinson AE: Promotion of Dnl4catalyzed DNA end-joining by the Rad50/Mre11/Xrs2 and Hdf1/Hdf2 complexes. Mol Cell 2001, 8:1105-1115.

13. Chovanec M, Wilson TE: Restricting the ligation step of non-homologous end-joining. DNA Repair (Amst) 2007, 6:1890-1893.

14. Wu D, Topper LM, Wilson TE: Recruitment and dissociation of nonhomologous end joining proteins at a DNA double-strand break in Saccharomyces cerevisiae. Genetics 2008, 178:1237-1249.

15. Alani E, Thresher R, Griffith JD, Kolodner RD: Characterization of DNAbinding and strand-exchange stimulation properties of $y$-RPA, a yeast single-strand-DNA-binding protein. J Mol Biol 1992, 227:54-71.

16. Moreau S, Morgan EA, Symington LS: Overlapping functions of the Saccharomyces cerevisiae Mre11, Exo1 and Rad27 nucleases in DNA metabolism. Genetics 2001, 159:1423-1433.

17. Melo JA, Cohen J, Toczyski DP: Two checkpoint complexes are independently recruited to sites of DNA damage in vivo. Genes Dev 2001, 15:2809-2821.

18. Benson FE, Baumann P, West SC: Synergistic actions of Rad51 and Rad52 in recombination and DNA repair. Nature 1998, 391:401-404.

19. New JH, Sugiyama T, Zaitseva E, Kowalczykowski SC: Rad52 protein stimulates DNA strand exchange by Rad51 and replication protein A. Nature 1998, 391:407-410.

20. Shinohara A, Ogawa T: Stimulation by Rad52 of yeast Rad51-mediated recombination. Nature 1998, 391:404-407.

21. Sung P: Function of yeast Rad52 protein as a mediator between replication protein A and the Rad51 recombinase. J Biol Chem 1997, 272:28194-28197.

22. Solinger JA, Lutz G, Sugiyama T, Kowalczykowski SC, Heyer WD: Rad54 protein stimulates heteroduplex DNA formation in the synaptic phase of DNA strand exchange via specific interactions with the presynaptic Rad51 nucleoprotein filament. J Mol Biol 2001, 307:1207-1221.

23. Fortin GS, Symington LS: Mutations in yeast Rad51 that partially bypass the requirement for Rad55 and Rad57 in DNA repair by increasing the stability of Rad51-DNA complexes. Embo J 2002, 21:3160-3170.

24. Sung P: Yeast Rad55 and Rad57 proteins form a heterodimer that functions with replication protein A to promote DNA strand exchange by Rad51 recombinase. Genes Dev 1997, 11:1111-1121.

25. Shi I, Hallwyl SC, Seong C, Mortensen U, Rothstein R, Sung P: Role of the Rad52 amino-terminal DNA binding activity in DNA strand capture in homologous recombination. J Biol Chem 2009, 284:33275-33284.

26. Mortensen UH, Bendixen C, Sunjevaric I, Rothstein R: DNA strand annealing is promoted by the yeast Rad52 protein. Proc Natl Acad Sci USA 1996, 93:10729-10734.

27. Shinohara A, Shinohara M, Ohta T, Matsuda S, Ogawa T: Rad52 forms ring structures and co-operates with RPA in single-strand DNA annealing. Genes Cells 1998, 3:145-156. 
28. Sugiyama T, Kantake N, Wu Y, Kowalczykowski SC: Rad52-mediated DNA annealing after Rad51-mediated DNA strand exchange promotes second ssDNA capture. Embo J 2006, 25:5539-5548.

29. Davis AP, Symington LS: RAD51-dependent break-induced replication in yeast. Mol Cell Biol 2004, 24:2344-2351.

30. Malkova A, Ivanov EL, Haber JE: Double-strand break repair in the absence of $R A D 51$ in yeast: a possible role for break-induced DNA replication. Proc Natl Acad Sci USA 1996, 93:7131-7136.

31. Morrow DM, Connelly C, Hieter P: "Break copy" duplication: a model for chromosome fragment formation in Saccharomyces cerevisiae. Genetics 1997, 147:371-382.

32. Karathanasis E, Wilson TE: Enhancement of Saccharomyces cerevisiae endjoining efficiency by cell growth stage but not by impairment of recombination. Genetics 2002, 161:1015-1027.

33. Takata M, Sasaki MS, Sonoda E, Morrison C, Hashimoto M, Utsumi $H$, Yamaguchi-Iwai Y, Shinohara A, Takeda S: Homologous recombination and non-homologous end-joining pathways of DNA double-strand break repair have overlapping roles in the maintenance of chromosomal integrity in vertebrate cells. Embo J 1998, 17:5497-5508.

34. Aylon $Y$, Liefshitz $B$, Kupiec M: The CDK regulates repair of double-strand breaks by homologous recombination during the cell cycle. Embo $J$ 2004, 23:4868-4875.

35. Ira G, Pellicioli A, Balijja A, Wang X, Fiorani S, Carotenuto W, Liberi G, Bressan D, Wan L, Hollingsworth NM, et al: DNA end resection, homologous recombination and DNA damage checkpoint activation require CDK1. Nature 2004, 431:1011-1017.

36. Zierhut C, Diffley JF: Break dosage, cell cycle stage and DNA replication influence DNA double strand break response. Embo J 2008, 27:1875-1885.

37. Gravel S, Chapman JR, Magill C, Jackson SP: DNA helicases Sgs1 and BLM promote DNA double-strand break resection. Genes Dev 2008, 22:2767-2772

38. Lengsfeld BM, Rattray AJ, Bhaskara $V$, Ghirlando R, Paull TT: Sae2 is an endonuclease that processes hairpin DNA cooperatively with the Mre11/ Rad50/Xrs2 complex. Mol Cell 2007, 28:638-651.

39. Limbo O, Chahwan C, Yamada Y, de Bruin RA, Wittenberg C, Russell P: Ctp1 is a cell-cycle-regulated protein that functions with Mre11 complex to control double-strand break repair by homologous recombination. $\mathrm{Mol}$ Cell 2007, 28:134-146.

40. Mimitou EP, Symington LS: Sae2, Exo1 and Sgs1 collaborate in DNA double-strand break processing. Nature 2008, 455:770-774.

41. Sartori AA, Lukas C, Coates J, Mistrik M, Fu S, Bartek J, Baer R, Lukas J, Jackson SP: Human CtIP promotes DNA end resection. Nature 2007, 450:509-514.

42. Zhu Z, Chung WH, Shim EY, Lee SE, Ira G: Sgs1 helicase and two nucleases Dna2 and Exo1 resect DNA double-strand break ends. Cell 2008, 134:981-994.

43. Huertas P, Cortes-Ledesma F, Sartori AA, Aguilera A, Jackson SP: CDK targets Sae2 to control DNA-end resection and homologous recombination. Nature 2008, 455:689-692.

44. Raderschall E, Golub El, Haaf T: Nuclear foci of mammalian recombination proteins are located at single-stranded DNA regions formed after DNA damage. Proc Natl Acad Sci USA 1999, 96:1921-1926.

45. Barlow JH, Lisby M, Rothstein R: Differential regulation of the cellular response to DNA double-strand breaks in G1. Mol Cell 2008, 30:73-85.

46. Alabert C, Bianco JN, Pasero P: Differential regulation of homologous recombination at DNA breaks and replication forks by the Mrc1 branch of the S-phase checkpoint. Embo J 2009, 28:1131-1141.

47. Barlow $\mathrm{JH}$, Rothstein R: Rad52 recruitment is DNA replication independent and regulated by $\mathrm{Cdc} 28$ and the Mec1 kinase. Embo J 2009, 28:1121-1130.

48. Antunez de Mayolo A, Lisby M, Erdeniz N, Thybo T, Mortensen UH, Rothstein R: Multiple start codons and phosphorylation result in discrete Rad52 protein species. Nucleic Acids Res 2006, 34:2587-2597.

49. Din S, Brill SJ, Fairman MP, Stillman B: Cell-cycle-regulated phosphorylation of DNA replication factor A from human and yeast cells. Genes Dev 1990, 4:968-977.

50. Dutta A, Stillman B: cdc2 family kinases phosphorylate a human cell DNA replication factor, RPA, and activate DNA replication. Embo J 1992, 11:2189-2199.

51. Fotedar R, Roberts JM: Cell cycle regulated phosphorylation of RPA-32 occurs within the replication initiation complex. Embo J 1992, 11:2177-2187.
52. Kim HS, Brill SJ: MEC1-dependent phosphorylation of yeast RPA1 in vitro. DNA Repair (Amst) 2003, 2:1321-1335.

53. Liu VF, Weaver DT: The ionizing radiation-induced replication protein A phosphorylation response differs between ataxia telangiectasia and normal human cells. Mol Cell Biol 1993, 13:7222-7231.

54. Anantha RW, Vassin VM, Borowiec JA: Sequential and synergistic modification of human RPA stimulates chromosomal DNA repair. J Biol Chem 2007, 282:35910-35923.

55. Blow JJ: Preventing re-replication of DNA in a single cell cycle: evidence for a replication licensing factor. J Cell Biol 1993, 122:993-1002.

56. Chevalier S, Blow Jj: Cell cycle control of replication initiation in eukaryotes. Curr Opin Cell Biol 1996, 8:815-821

57. Coverley D, Downes CS, Romanowski P, Laskey RA: Reversible effects of nuclear membrane permeabilization on DNA replication: evidence for a positive licensing factor. J Cell Biol 1993, 122:985-992.

58. Diffley JF, Cocker JH, Dowell SJ, Rowley A: Two steps in the assembly of complexes at yeast replication origins in vivo. Cell 1994, 78:303-316.

59. Diffley JF, Labib K: The chromosome replication cycle. J Cell Sci 2002, 115:869-872.

60. Cha RS, Kleckner N: ATR homolog Mec1 promotes fork progression, thus averting breaks in replication slow zones. Science 2002, 297:602-606.

61. Lopes M, Cotta-Ramusino C, Pellicioli A, Liberi G, Plevani P, Muzi-Falconi M, Newlon CS, Foiani M: The DNA replication checkpoint response stabilizes stalled replication forks. Nature 2001, 412:557-561.

62. Tercero JA, Diffley JF: Regulation of DNA replication fork progression through damaged DNA by the Mec1/Rad53 checkpoint. Nature 2001, 412:553-557.

63. Naylor ML, Li JM, Osborn AJ, Elledge SJ: Mrc1 phosphorylation in response to DNA replication stress is required for Mec1 accumulation at the stalled fork. Proc Natl Acad Sci USA 2009, 106:12765-12770.

64. Szyjka SJ, Viggiani CJ, Aparicio OM: Mrc1 is required for normal progression of replication forks throughout chromatin in S. cerevisiae. Mol Cell 2005, 19:691-697.

65. Tourriere H, Versini G, Cordon-Preciado V, Alabert C, Pasero P: Mrc1 and Tof1 promote replication fork progression and recovery independently of Rad53. Mol Cell 2005, 19:699-706.

66. Gambus A, Jones RC, Sanchez-Diaz A, Kanemaki M, van Deursen F, Edmondson RD, Labib K: GINS maintains association of Cdc45 with MCM in replisome progression complexes at eukaryotic DNA replication forks. Nat Cell Biol 2006, 8:358-366.

67. Smolka MB, Albuquerque CP, Chen SH, Zhou H: Proteome-wide identification of in vivo targets of DNA damage checkpoint kinases. Proc Natl Acad Sci USA 2007, 104:10364-10369.

68. Irmisch A, Ampatzidou E, Mizuno K, O'Connell MJ, Murray JM: Smc5/6 maintains stalled replication forks in a recombination-competent conformation. Embo J 2009, 28:144-155.

69. Cobb JA, Bjergbaek L, Shimada K, Frei C, Gasser SM: DNA polymerase stabilization at stalled replication forks requires Mec1 and the RecQ helicase Sgs1. Embo J 2003, 22:4325-4336.

70. Gangloff S, Soustelle C, Fabre F: Homologous recombination is responsible for cell death in the absence of the Sgs1 and Srs 2 helicases. Nat Genet 2000, 25:192-194.

71. Mankouri HW, Hickson ID: Top3 processes recombination intermediates and modulates checkpoint activity after DNA damage. Mol Biol Cell 2006, 17:4473-4483.

72. Shor E, Gangloff S, Wagner M, Weinstein J, Price G, Rothstein R: Mutations in homologous recombination genes rescue top3 slow growth in Saccharomyces cerevisiae. Genetics 2002, 162:647-662.

73. Lisby $M$, Rothstein $R$, Mortensen UH: Rad52 forms DNA repair and recombination centers during S phase. Proc Natl Acad Sci USA 2001, 98:8276-8282

74. Merrill BJ, Holm C: A requirement for recombinational repair in Saccharomyces cerevisiae is caused by DNA replication defects of mec1 mutants. Genetics 1999, 153:595-605.

75. Tong $A H$, Lesage $G$, Bader GD, Ding $H, X u H$, Xin X, Young J, Berriz GF, Brost RL, Chang $M$, et al: Global mapping of the yeast genetic interaction network. Science 2004, 303:808-813.

76. Sacher M, Pfander B, Hoege C, Jentsch S: Control of Rad52 recombination activity by double-strand break-induced SUMO modification. Nat Cell Biol 2006, 8:1284-1290. 
77. Torres-Rosell J, Sunjevaric I, De Piccoli G, Sacher M, Eckert-Boulet N, Reid R, Jentsch S, Rothstein R, Aragon L, Lisby M: The Smc5-Smc6 complex and SUMO modification of Rad52 regulates recombinational repair at the ribosomal gene locus. Nat Cell Biol 2007, 9:923-931.

78. Outwin EA, Irmisch A, Murray JM, O'Connell MJ: Smc5-Smc6-dependent removal of cohesin from mitotic chromosomes. Mol Cell Biol 2009, 29:4363-4375

79. Zhao X, Blobel G: A SUMO ligase is part of a nuclear multiprotein complex that affects DNA repair and chromosomal organization. Proc Natl Acad Sci USA 2005, 102:4777-4782.

80. Burgess RC, Lisby M, Altmannova V, Krejci L, Sung P, Rothstein R: Localization of recombination proteins and Srs2 reveals antirecombinase function in vivo. J Cell Biol 2009, 185:969-981.

doi:10.1186/1747-1028-5-7

Cite this article as: Barlow and Rothstein: Timing is everything: cell cycle control of Rad52. Cell Division 2010 5:7.

\section{Submit your next manuscript to BioMed Central} and take full advantage of:

- Convenient online submission

- Thorough peer review

- No space constraints or color figure charges

- Immediate publication on acceptance

- Inclusion in PubMed, CAS, Scopus and Google Scholar

- Research which is freely available for redistribution

Submit your manuscript at www.biomedcentral.com/submit 